\title{
Plano de gestão na cadeia de comercialização do mel no Sertão da Paraiba
}

\author{
Management plan in the honey marketing chain in the Hinterland of Paraiba \\ Plan de gestión en la cadena de comercialización de miel en Sertão da Paraiba
}

\author{
José Cândido da Silva Nóbrega \\ ORCID: https://orcid.org/0000-0002-0976-3763 \\ Universidade Federal de Campina Grande, Brasil \\ E-mail: jcandidosn@uol.com.br \\ Francisco das Chagas Bezerra Neto \\ ORCID: https://orcid.org/0000-0001-6232-4383 \\ Universidade Federal de Campina Grande, Brasil \\ E-mail: chagasneto237@gmail.com \\ Aline Carla de Medeiros \\ ORCID: https://orcid.org/0000-0002-0161-3541 \\ Universidade Federal de Campina Grande, Brasil \\ E-mail: alinecarla.edu@gmail.com \\ Patrício Borges Maracajá \\ ORCID: https://orcid.org/0000-0003-4812-0389 \\ Universidade Federal de Campina Grande, Brasil \\ E-mail: patriciomaracaja@gmail.com
}

\begin{abstract}
Resumo
Esse estudo apresentou o plano de gestão na cadeia de comercialização do mel no sertão da Paraíba. A empresa que se pretende abrir terá o nome fictício de MEL ORGÂNICO POMBALENSE. Ela se diferenciará das concorrentes, pois oferecerá aos consumidores produtos orgânicos. O principal motivo para esta proposta é que atualmente não há nenhuma empresa especializada na região de Pombal em mel orgânico certificado, ou pelo menos não em evidência ou quantidade, que desenvolva um trabalho semelhante, portanto acredito que estes diferenciais possam agregar valor ao processo de venda, criando uma carteira fiel de clientes satisfeitos, garantindo boa rentabilidade, sucesso e prospecção do negócio. $\mathrm{O}$ foco da empresa será um atendimento premium de alta qualidade para o mercado de mel orgânico, hoje em dia carente de uma gestão profissional e com foco na satisfação do cliente. Teremos venda direta de produtos no varejo para os clientes. Concluiu-se que ao vender mel no mercado, é preciso levar em consideração uma série de questões que não podemos ignorar é que muito poucos comerciantes que não têm planos econômicos e, portanto, acabam falhando, por isso temos de ter um plano econômico também definido para este tipo de negócio de venda de mel.
\end{abstract}

Palavras-chave: Mel; Mel orgânico; Plano de gestão.

\begin{abstract}
This study presented the management plan in the honey commercialization chain in the interior of the state of Paraíba. The company that intends to open will have the fictitious name of MEL ORGANIC POMBALENSE. It will differentiate itself from competitors as it will offer consumers organic products. The main reason for this proposal is that currently there is no company specialized in the region of Pombal certified organic honey, or at least not in evidence or quantity, that develops a similar work, so I believe that these differentials can add value to the sales process, creating a loyal portfolio of satisfied customers, ensuring good profitability, success and business prospecting. The focus of the company will be a premium service of high quality for the market of organic honey, nowadays lacking a professional management and with focus on the satisfaction of the client. We will have direct sales of products in retail for customers. It was concluded that when selling honey on the market, we need to take into account a number of issues that we can not ignore is that very few traders who do not have economic plans and therefore end up failing, so we must have an economic plan also defined for this type of business selling honey.
\end{abstract}

Keywords: Honey; Organic honey; Management plan.

\section{Resumen}

Este estudio presentó el plan de manejo de la cadena de comercialización de la miel en el interior de Paraíba. La empresa que se abrirá tendrá el nombre ficticio de MIEL ORGÁNICA POMBALENSE. Se diferenciará de la competencia, ya que ofrecerá a los consumidores productos orgánicos. El principal motivo de esta propuesta es que actualmente no existe ninguna empresa especializada en la región de Pombal en miel orgánica certificada, o al menos no en evidencia o cantidad, que desarrolle un trabajo similar, por lo que creo que estos diferenciales pueden agregar valor al proceso de venta., creando una cartera leal de clientes satisfechos, asegurando buena rentabilidad, éxito y prospección comercial. El foco de la compañía estará en un servicio premium de alta calidad para el mercado de la miel orgánica, hoy en día 
necesitando una gestión profesional y enfocado en la satisfacción del cliente. Tendremos venta directa de productos al por menor a los clientes. Se concluyó que a la hora de vender miel en el mercado, es necesario tener en cuenta una serie de cuestiones que no podemos ignorar es que son muy pocos los comerciantes que no tienen planes económicos y, por tanto, acaban fracasando, por eso tenemos tener también definido un plan económico para este tipo de negocio de venta de miel.

Palabras clave: Miel; Miel ecológica; Plan de gestión.

\section{Introdução}

O comércio de mel e seus derivados têm crescido nos últimos anos. Visualizando esse crescimento principalmente com a abertura ao comércio exterior na década de 90, observa-se que há um nicho de um novo mercado que pode ser aberto em Pombal- Paraíba, para atendimento dos consumidores locais e de potenciais consumidores no exterior.

A empresa que se pretende abrir terá o nome fictício de MEL ORGÂNICO POMBALENSE. Ela se diferenciará das concorrentes, pois oferecerá aos consumidores produtos orgânicos. A empresa será de varejo em Pombal e realizará a distribuição para comerciantes em outras cidades.

Produtos orgânicos possuem atenções especiais, tais como, eles devem que ser mantidos a uma distância de pelo menos três quilômetros de quaisquer contaminantes como terras não-orgânicas ou fábricas. A eliminação de todas as substâncias químicas adicionará algumas dificuldades e desafios, mas a recompensa é o diferencial com a venda de produtos com o rótulo de orgânico que comanda preços premium (Serviço Brasileiro de Apoio às Micro e Pequenas Empresas [SEBRAE], 2015).

A empresa almeja se estabelecer na cidade de Pombal na Paraíba, mas pretende comercializar seus produtos não apenas na cidade, ela também tentará adentrar no comércio exterior. Atentando para a informação que em 2014, o Brasil exportou um recorde de 100 milhões de dólares de mel e 30\% do que era orgânico (Ministério da Agricultura, Pecuária e Abastecimento, 2014).

Essa busca por abrir fontes de vendas no exterior, veio do conhecimento de que o consumo de mel no Brasil ainda é pequeno, as empresas do setor assim vêem nas exportações uma maneira de crescer e expandir receitas. No ano passado, o Brasil registrou forte crescimento nas vendas para o mercado internacional e subiu seis posições no ranking mundial, ocupando agora o oitavo lugar em valor (SEBRAE, 2015).

Em 2014, houve uma grande demanda no mercado internacional e o aumento do dólar aumentou as exportações (SEBRAE, 2015). Outro fator favorável para o setor é que o mel deve ganhar força por estar ligado ao conceito de alimentação saudável, mas de outro lado o setor tem o preço como principal barreira, influenciada pelo custo de produção e da alta do dólar. Os Estados Unidos são o principal comprador do produto brasileiro. $\mathrm{O}$ mel brasileiro é bem visto no mercado por ser limpo e livre de resíduos.

Abelhas brasileiras estão "africanizadas", ou seja, elas são mais resistentes e não necessitam, por exemplo, o uso de medicamentos. Geralmente novos entrantes no mercado começam a exportar com vendas a granel. Ao longo do tempo, e para ganhar a confiança dos compradores, projeta-se que a MEL ORGÂNICO POMBALENSE pode começar a carimbar rótulo do produto com a sua marca e, desta forma, agregar valor ao negócio e ampliando as vendas (Ministério da Agricultura, Pecuária e Abastecimento, 2014).

\section{Descrição do Negócio Proposto}

\section{Proposição de Negócio}

A proposta deste trabalho é a criação da empresa MEL ORGÂNICO POMBALENSE. A empresa terá sede na cidade de Pombal e realizará a distribuição para a cidade de Pombal e as cidades vizinhas. Em um segundo momento a empresa pretende se expandir para o comércio exterior.

O principal motivo para esta proposta é que atualmente não há nenhuma empresa especializada na região de Pombal em 
mel orgânico certificado, ou pelo menos não em evidência ou quantidade, que desenvolva um trabalho semelhante, portanto acredito que estes diferenciais possam agregar valor ao processo de venda, criando uma carteira fiel de clientes satisfeitos, garantindo boa rentabilidade, sucesso e prospecção do negócio.

\section{Business Model Canvas - Visão Geral}

- Parcerias principais: Financeiras e Bancos

- Atividades principais: Venda de mel e produção derivados do mel

- Loja física, pessoas capacitadas e com experiência na venda de mel.

- Proposta de valor: Produtos de mel orgânicos diversificados e atendimento premium.

- Relacionamento com os clientes: Investimento em marketing online e offline e relacionamento diretamente com os clientes.

- Venda varejo através da loja física e da internet.

- Segmento de clientes: A, B, C, D, ambos os sexos. Com relação à segmentação de clientes, atenderemos diversos perfis de pessoas, pois o mercado de produtos de mel é muito abrangente e trabalharemos com diferentes linhas de produtos.

- Estrutura de Custos: Custos da loja física, custos de salários, custos fixos e variáveis, despesas com vendas, investimentos em marketing.

- Fontes de receita: Venda de mel orgânico e seus derivados com preços competitivos.

\section{Segmento de clientes}

Ao combinar o seu segmento de clientes à sua proposta de valor, o gerenciador pode conseguir um fluxo de receitas mais lucrativo. Por isso, é fundamental para uma organização a compreender o trade-off entre os diferentes segmentos de clientes e selecionar cuidadosamente qual o segmento que quer atingir. Em seguida, a organização deve criar uma proposta de valor e empregar um modelo de negócio mais adequado para atender as necessidades do seu segmento de clientes escolhidos. Uma organização pode categorizar os consumidores em grupos distintos se eles têm as seguintes características. Definir grupos de clientes ajuda no planejamento de uma necessidade específica que justifica a criação de um produto para coincidir com esta necessidade. O grupo precisa de um canal de distribuição separado para ser alcançado. Os grupos exigem relações de diferentes tipos. Há uma diferença muito clara no nível de rentabilidade cada grupo representa para a organização. Cada grupo de consumidores se sente forte o suficiente para pagar por uma versão diferente do produto ou serviço, adaptado às suas preferências.

Na elaboração desse Plano de Negócio, o pesquisador foi a campo e passou um questionário para conhecer mais os possíveis clientes, foram entrevistados 50 consumidores na cidade de Pombal e nas cidades vizinhas.

Com relação à segmentação de clientes, atenderemos diversos perfis de pessoas, pois o mercado de produtos de mel é muito abrangente e trabalharemos com diferentes linhas de produtos.

Em relação à idade dos consumidores dos 100\% dos entrevistados 40\% tem mais de 49 anos, 26\% tem entre 18-29 anos, $20 \%$ possui entre 40 a 49 anos e $14 \%$ declarou ter entre 30 a 39 anos. 
Gráfico 1: Idade.

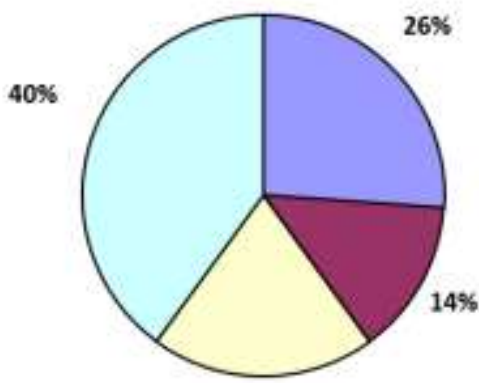

\begin{tabular}{l|l}
\hline & 18 a 29 Anos \\
$\square$ & 30 a 39 Anos \\
$\square$ & 40 a 49 Anos \\
$\square$ & Mais de 50 Anos
\end{tabular}

$20 \%$

Fonte: Autores (2018).

Perguntou-se aos consumidores: Qual seu nível de escolaridade? Dos 100\% dos entrevistados, 30\% disseram ter Ensino Fundamental Completo, $28 \%$ possuem Ensino Médio Completo, 12\% possuem Ensino Fundamental Incompleto, $12 \%$ possuem Ensino Superior Incompleto e 8\% possuem Ensino Superior Completo.

\section{Qual seu nível de escolaridade?}

Gráfico 2: Escolaridade.
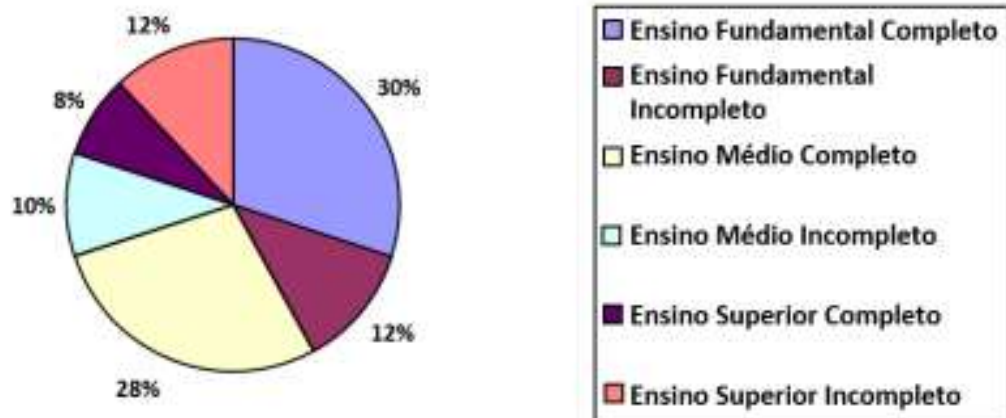

Fonte: Autores (2018).

Perguntou-se: Você consome mel orgânico e seus derivados? Dos 100\% dos entrevistados, $40 \%$ disseram que às vezes, $30 \%$ disseram que sempre, $22 \%$ disseram que nem sempre e $4 \%$ disseram que nunca.

Você consome mel orgânico e seus derivados?

Gráfico 3: Consumo de mel.

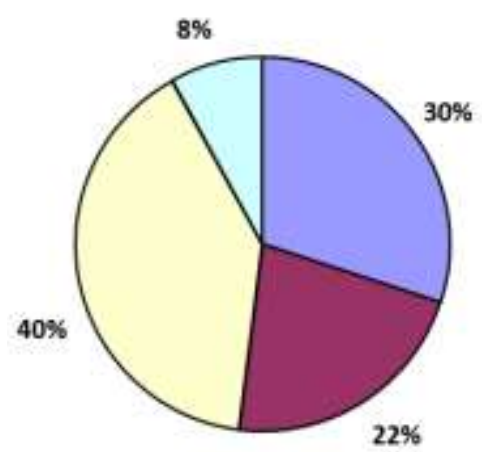

\begin{tabular}{|l|}
\hline Sempre \\
$\square$ Nem Sempre \\
$\square$ As vezes \\
$\square$ Nunca \\
\hline
\end{tabular}

Fonte: Autores (2018). 
Perguntou-se aos consumidores: Tem facilidade de encontrar mel orgânico e seus derivados no comércio local? Dos $100 \%$ dos entrevistados, $52 \%$ disseram que sempre, $20 \%$ disseram que às vezes, $14 \%$ disseram que nem sempre e $14 \%$ disseram que nunca.

Tem facilidade de encontrar mel orgânico e seus derivados no comércio local?

Gráfico 4: Compra de mel no Comércio Local.
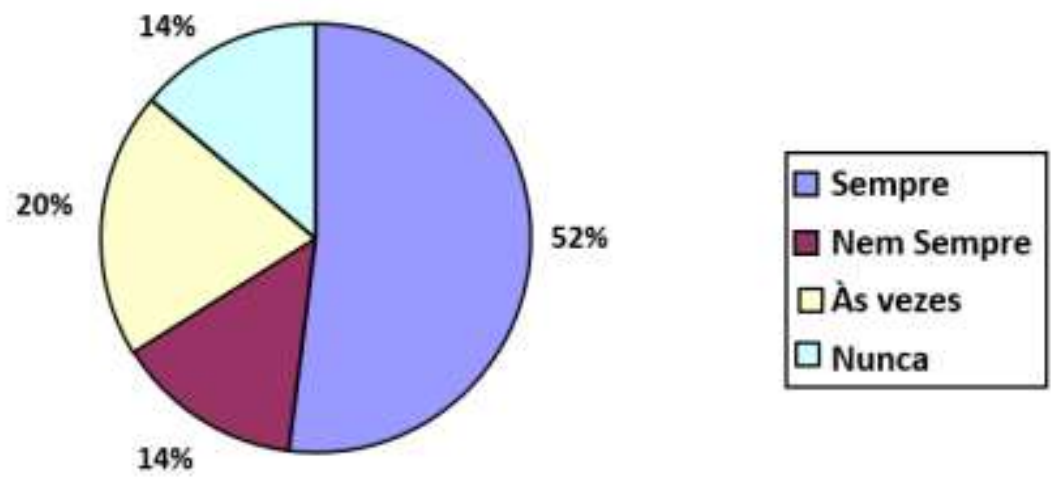

Fonte: Autores (2018).

Perguntou-se: Considera o mel orgânico e seus derivados na cidade de Pombal de qualidade? Dos $100 \%$ dos entrevistados, $54 \%$ disseram que sempre, $28 \%$ disseram que às vezes, $16 \%$ disseram que nem sempre e $2 \%$ disseram que nunca.

\section{Considera o mel orgânico e seus derivados na cidade de Pombal de qualidade?}

Gráfico 5: Qualidade do Mel de Pombal.
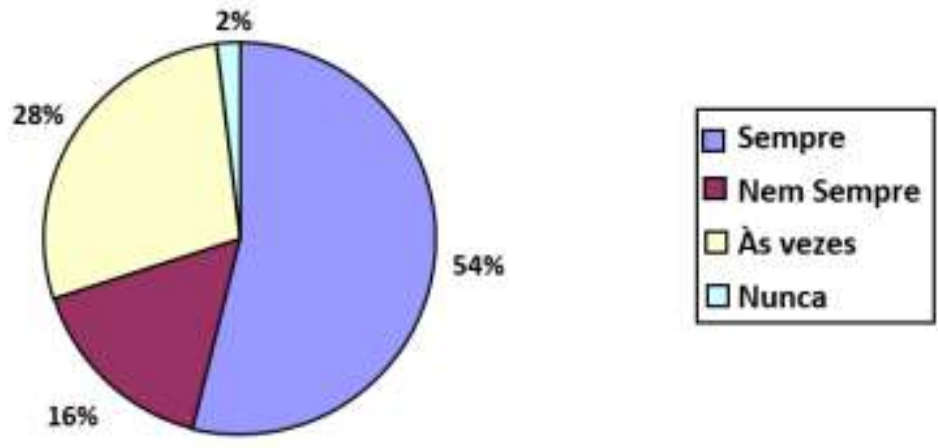

Fonte: Autores (2018).

Perguntou-se: Gostaria de ter acesso a mais derivados do mel orgânico no comércio local? Dos $100 \%$ dos entrevistados $80 \%$ disseram que sempre, $8 \%$ disseram que nem sempre, $8 \%$ disseram que às vezes e $4 \%$ disseram que nunca. 


\section{Gostaria de ter acesso a mais derivados do mel orgânico no comércio local?}

Gráfico 6: Acesso à variedade de Mel Orgânico em Pombal.
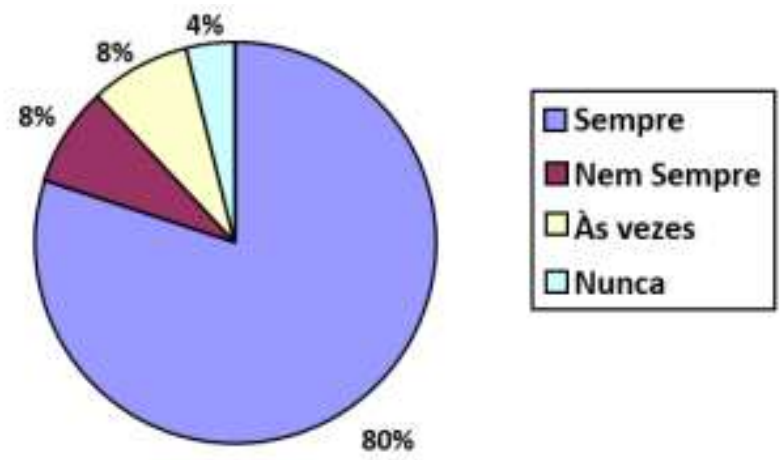

Fonte: Autores (2018).

Perguntou-se: Sabe o que é mel orgânico? Dos 100\% dos entrevistados, 50\% disseram que sim, 20\% disseram que mais ou menos, $20 \%$ disseram que nunca ouviram falar e $10 \%$ disseram que talvez.

\section{Sabe o que é mel orgânico?}

Gráfico 7: Conhecimento sobre mel orgânico.

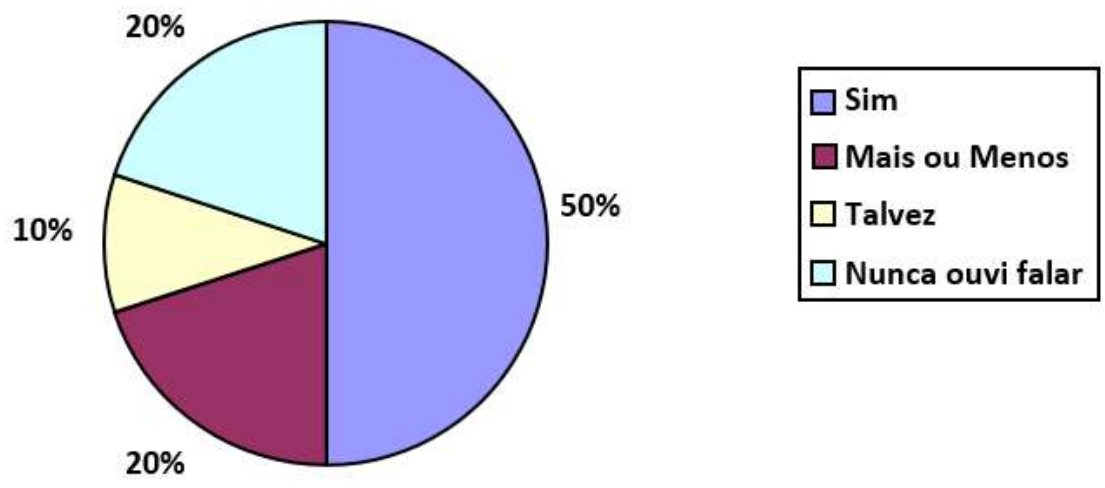

Fonte: Autores (2018).

Perguntou-se: Qual é a média do preço do litro de mel? Dos 100\% dos entrevistados, $44 \%$ disseram que entre 20 a 29 reais, $36 \%$ disseram entre 10 a 19 reais, $18 \%$ não sabem e $12 \%$ disseram entre 30 a 39 reais. 
Qual é a média do preço do litro de mel?

Gráfico 8: Preço do litro mel.

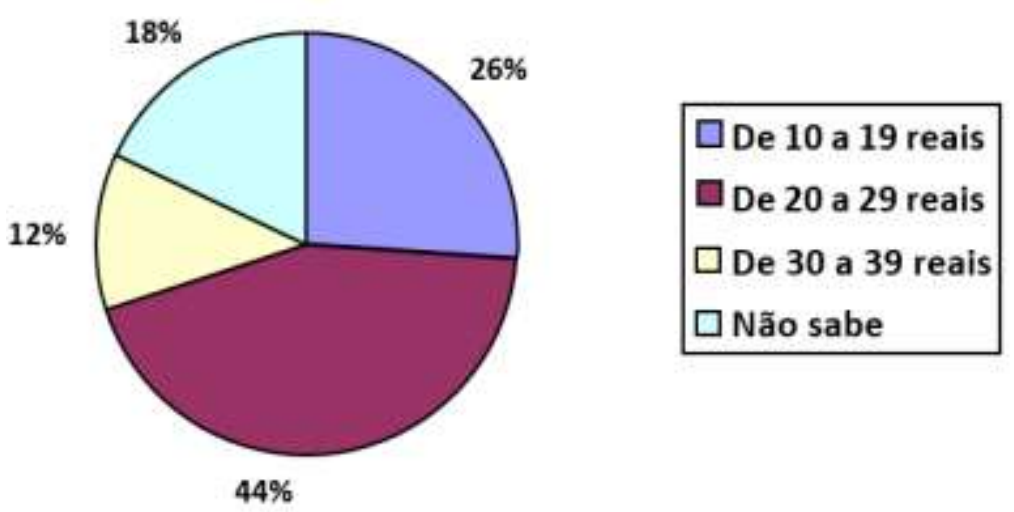

Fonte: Autores (2018).

Perguntou-se: O que chama mais atenção para comprar mel? Dos 100\% dos entrevistados, $40 \%$ disseram que é a procedência, $34 \%$ disseram que é a aparência, $16 \%$ disseram que é o preço e $10 \%$ disseram que é a embalagem.

\section{O que chama mais atenção para comprar mel?}

Gráfico 9: Motivação para compra do mel.
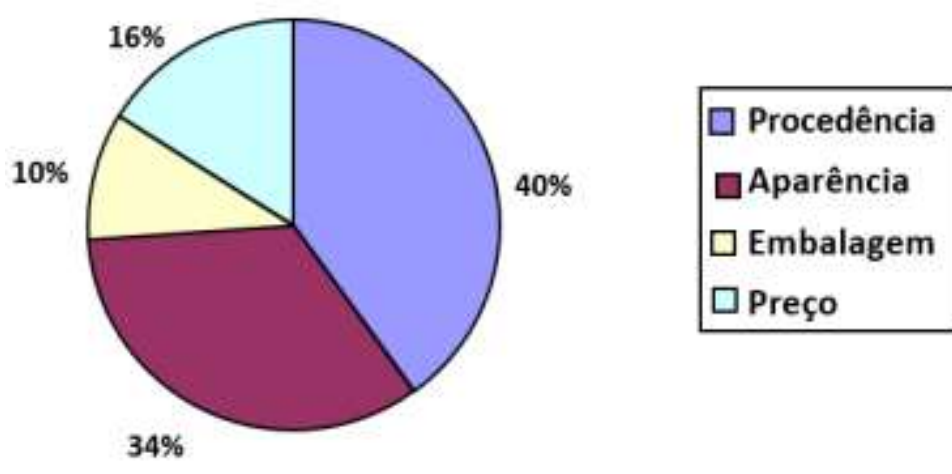

Fonte: Autores (2018).

Segmentação Psicográfica:

Acredito que boa parte dos clientes que atingiremos terão idade média de 40-49 anos, casados ou não, com estilo de vida urbano.

Segmentação Geográfica:

A loja estará localizada na área metropolitana de Pombal, portanto a maior parte dos clientes atendidos será desta região.

Segmentação Comportamental:

Acredito que os clientes serão em maioria de classe média, conectados em novidades, preços e oportunidades, que buscam benefícios monetários e comportamentais em suas compras, que valorizam um bom serviço e transparência e tranquilidade. 


\section{Proposta de valor}

A proposta de valor da MEL ORGÂNICO POMBALENSE com padrão de atendimento e excelência de uma loja pode ser resumida ao alto nível de atendimento e acompanhamento da venda pela equipe, além da melhor oferta e agregação de valor ao cliente, através de uma boa qualificação deste consumidor para que seja oferecido o melhor product/ proposta.

Atualmente, vendedores estão se tornando executivos de vendas com alto conhecimento dos produtos e ofertas da concorrência, que se envolvem em todas as etapas da compra do cliente, desde o entendimento da necessidade/perfil do consumidor até o acompanhamento do pós venda através da análise da satisfação dos produtos.

O cliente que optar por comprar conosco terá um atendimento muito superior ao da concorrência, que em grande parte tem foco somente na venda de produtos derivados de mel orgânicos e de alta qualidade.

\section{Canais de distribuição}

Distribuição é a ferramenta de marketing que liga a produção ao consumo, e sua função é fazer com que o produto à disposição do consumidor final na hora que precisar e onde você quer comprar.

A loja contará com exposição de produtos na sua loja física em Pombal, a mesma se enquadra no ramo varejista e também atenderá as cidades vizinhas.

Teremos também atendimento personalizado através de nosso website, onde um de nossos executivos de vendas entrará em contato com os prospects em no máximo $24 \mathrm{hrs}$ para entender suas necessidades e atender com o melhor produto possível.

Nosso website terá sempre o nosso estoque atualizado com fotos padronizadas dos produtos, com descrição, etc.

\section{Relacionamento com clientes}

Considerarei todas as etapas do atendimento ao cliente como "Relacionamento com Clientes", e listarei cada uma das etapas abaixo.

A primeira delas é a prospecção e gerenciamento de consultas, que pode ocorrer pelo website ou anúncios, telefone, atividades de prospecção em eventos. Teremos uma equipe dedicada para essas atividades, com metas semanais e indicadores de desempenho como, por exemplo, taxas de conversão.

A segunda etapa é a qualificação do cliente, sendo essa atividade responsabilidade do vendedor e do gerente de vendas. Nesta etapa do atendimento a equipe de vendas é responsáveis por entender diversas características e opiniões dos clientes, para dessa maneira conseguirmos entregar o melhor produto possível.

A terceira etapa do atendimento é a apresentação do produto, e esta deve ser feita com o objetivo de criar valor para o cliente explorando todo o conhecimento adquirido na etapa qualificação. Com todas as informações sobre o cliente poderemos atendê-lo com alta qualidade e conhecimento de maneira que suas vontades sejam atendidas.

A quarta etapa do atendimento é o test-drive, e nele os vendedores poderão demonstrar na prática tudo o que foi explicado na etapa apresentação de produto.

A quinta etapa é a negociação e acordo sobre a venda, onde preços e prazos serão negociados com foco nas demandas do cliente, por exemplo "melhor preço à vista" ou "menor parcela possível". Nesta etapa outros serviços serão oferecidos para o cliente, como por exemplo o oferecimento de novos produtos.

A sexta etapa do relacionamento com o cliente é o gerenciamento da satisfação, que poderá ser realizado por conversas na loja diretamente com o consumidor e também por pesquisas de satisfação que passaremos por email.

\section{Fluxo de receitas}

Nosso modelo de negócios as receitas serão obtidas principalmente das fontes abaixo: 
- venda de produtos de mel orgânico.

\section{Recursos Chave}

Para oferecer uma proposta de valor aos nossos clientes e manter um relacionamento duradouro, de maneira a fidelizar e reter estes clientes, de maneira que eles voltem a comprar conosco e indiquem amigos e familiares, precisaremos de:

\section{- $\quad$ Estrutura física}

Um espaço para vendas e pós venda, com excelente padrão, ampla e com capacidade para demonstração de diversos produtos. Essa loja deverá estar bem localizada em uma região de alto fluxo de passantes do nosso público-alvo, com recursos de entretenimento para a família como, por exemplo, uma área de convivência com bebidas, comidas e televisão, assim como um espaço kids para diversão das crianças.

\section{- Estrutura humana}

Os colaboradores de vendas e pós-venda deverão ser profissionais de destaque no mercado com colaboradores com mais de 15 anos de experiência em Gestão de Negócios, aptos para atender as necessidades específicas de cada cliente. As instalações modernas, totalmente Informatizadas e munidas de equipamentos de comunicação de última geração, consagrarão a qualidade do nosso serviço. Além destes itens, a estabilidade do nosso quadro e talento para encontrar as melhores soluções, compatíveis com a realidade de cada empresa, serão responsáveis pelo nosso sucesso.

Formação do Patrimônio na Empresa formada pelos seus sócios Custos de Instalação da Empresa

Para se obter a licença prévia de funcionamento e vigilância sanitária, foi consultada a Prefeitura, a qual verificou se a empresa poderia ser aberta no local desejado, de acordo com a lei de zoneamento urbano. Foi consultado ainda o órgão ambiental de cidade de Pombal sobre a aprovação do local, em termos ambientais. O objetivo foi avaliar se o ramo de atividade é compatível com o endereço e a situação do imóvel. O imóvel foi adquirido após a verificação da viabilidade do funcionamento.

\section{Local}

A empresa tem um custo fixo mensal com aluguel e IPTU (Imposto predial e territorial conforme descritos a seguir:

\begin{tabular}{|c|c|}
\hline \multicolumn{2}{|c|}{ Quadro 1: Custos de Instalação da Empresa. } \\
\hline Tipo de Custos & Valor $(\mathbf{R} \$)$ \\
\hline Aluguel (mensal) & $15.000,00$ \\
\hline IPTU (Anual) & $6.000,00$ \\
\hline 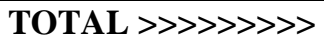 & $21.000,00$ \\
\hline
\end{tabular}

Fonte: Desenvolvido pelos autores do projeto (2016).

O quadro acima mostra que com aluguel (mensal ) e IPTU (anual) serão gastos $\mathrm{R} \$ 21.000,00$. As despesas fixas e variáveis estão descritas conforme a seguir: 


\begin{tabular}{|l|l|}
\hline \multicolumn{2}{|c|}{ Quadro 2: Despesas Mensais (R\$ mil). } \\
\hline Descrição & R\$ \\
\hline FIXO & $15.500,00$ \\
\hline Aluguel das instalações + IPTU & $2.500,00$ \\
Tarifas de água, luz e telefone & 200,00 \\
Acesso internet banda larga & $2.000,00$ \\
Material de escritório, limpeza, conservação & \\
e consumo & $1.200,00$ \\
Honorários contábeis & 300,00 \\
Despesas Bancárias & 500,00 \\
Manutenção do & \\
website & $1.000,00$ \\
\hline Outras despesas & $\mathbf{2 3 . 2 0 0 , 0 0}$ \\
\hline Total FIXO &
\end{tabular}

\begin{tabular}{|l|l|}
\hline VARIÁVEL \\
\hline Mala direta & $1.000,00$ \\
Outros & 0,00 \\
\hline Total VARIÁVEL & $\mathbf{1 . 0 0 0 , 0 0}$ \\
\hline \multicolumn{2}{|c|}{ Fonte: Desenvolvido pelos autores do projeto (2016). } \\
\hline
\end{tabular}

Quadro 3: Resumo da mão-de-obra requerida (R\$).

\begin{tabular}{|c|c|c|c|c|c|}
\hline Discriminação & Funcionários & Salário & Encargos & $\begin{array}{c}\text { Custo mensal } \\
\text { (salários e } \\
\text { encargos) }\end{array}$ & $\begin{array}{c}\text { Custo anual } \\
\text { (salários e } \\
\text { encargos) }\end{array}$ \\
\hline Gerente & 1 & $2,500,00$ & 908,00 & $3.408,00$ & $40.896,00$ \\
\hline Recepcionista & 1 & 900,00 & 326,88 & $1.226,88$ & $14.722,56$ \\
\hline Assistente Contábil & 1 & 900,00 & 326,88 & $1.226,88$ & $14.722,56$ \\
\hline Assistente ADM & 1 & 900,00 & 326,88 & $1.226,88$ & $14.722,56$ \\
\hline Supervisor & 1 & $1.500,00$ & 544,80 & $2.044,80$ & $24.532,60$ \\
\hline Motorista & 1 & 800,00 & 290,56 & $1.090,56$ & $13.086,72$ \\
\hline Auxiliar de serviços & 5 & 800,00 & $1.452,80$ & $5.452,80$ & $65.433,60$ \\
\hline gerais & & & & & \\
\hline Vendedores & 5 & $1.100,00$ & $1.997,60$ & $7.497,60$ & $89.971,20$ \\
\hline Auxiliar de Vendas & 1 & 600,00 & 217,92 & 817,92 & $9.815,04$ \\
\hline Total & & & $6.392,32$ & $23.992,32$ & $287.907,84$ \\
\hline
\end{tabular}

Fonte: Desenvolvido pelos autores do projeto (2016).

O salário da mão-de-obra contratada mensalmente custará a empresa R \$ 17.600, enquanto que o custo anual será de R\$ $287.907,84$. 


\section{Encargos sociais}

\begin{tabular}{|c|c|}
\hline \multicolumn{2}{|c|}{ Quadro 4: Encargos Sociais. } \\
\hline Descriminação & $\%$ \\
\hline INSS & \\
FGTS & $8,00 \%$ \\
$13^{\text {o } ~}$ Férias & $8,33 \%$ \\
Férias & $8,33 \%$ \\
1/3 Férias & $2,78 \%$ \\
FGTS Verbas Recisorias & $1,74 \%$ \\
Multa FGTS 50\% & $4,87 \%$ \\
Aviso Previo Trab & $2,27 \%$ \\
\hline Total & $\mathbf{3 6 , 3 2 \%}$ \\
\hline
\end{tabular}

Fonte: Desenvolvido pelos autores do projeto (2016).

Entre os encargos sociais ressalta-se o INSS, FGTS, $13^{\circ}$ e Férias, 1/3 Férias, FGTS Verbas Rescisórias, Multa FGTS $50 \%$ e Aviso prévio, todos esses encargos ficaram na ordem de $36,32 \%$.

\section{Pró-labore dos sócios}

\begin{tabular}{|c|c|c|c|c|}
\hline \multicolumn{5}{|c|}{ Quadro 5: Pró-Labore (R\$). } \\
\hline Sócios & $\begin{array}{c}\text { Retirada } \\
\text { Mensal }\end{array}$ & $\begin{array}{c}\text { Encargos } \\
\mathbf{2 0 \%}\end{array}$ & $\begin{array}{c}\text { Total Retirada } \\
\text { Mensal }\end{array}$ & Total Anual \\
\hline Sócio-proprietário 1 & $6.000,00$ & $1.200,00$ & $7.200,00$ & $86.400,00$ \\
\hline Sócio- proprietário 2 & $6.000,00$ & $1.200,00$ & $7.200,00$ & $86.400,00$ \\
\hline TOTAL & $\mathbf{1 2 . 0 0 0 , 0 0}$ & $\mathbf{2 . 4 0 0 , 0 0}$ & $\mathbf{1 8 7 . 2 0 0 , 0 0}$ & $\mathbf{1 7 2 . 8 0 0 , 0 0}$ \\
\hline
\end{tabular}

Fonte: Desenvolvido pelos autores do projeto (2016).

O Pró-labore dos sócios mensal será de R \$12.000,00 e o total anual será de R \$ 172.800,00.

\section{Dividendos}

\begin{tabular}{|l|l|l|}
\hline \multicolumn{3}{|c|}{ Quadro 6: Dividendos (R\$). } \\
\hline Sócios & Mensal & Anual \\
\hline Sócio 1 & $4.000,00$ & $40.000,00$ \\
\hline Sócio 2 & $4.000,00$ & $40.000,00$ \\
\hline TOTAL & $\mathbf{8 . 0 0 0 , 0 0}$ & $\mathbf{8 0 . 0 0 0 , 0 0}$ \\
\hline
\end{tabular}

Fonte: Desenvolvido pelos autores do projeto (2016). 
Os dividendos mensais dos sócios estão na ordem de $\mathrm{R} \$ 8.000,00$ mensal e 80.000,00.

\section{Honorários dos Consultores}

\begin{tabular}{|c|c|c|c|c|}
\hline \multicolumn{5}{|c|}{ Quadro 7: Consultoria Gestão ( R\$ ). } \\
\hline Tipo & Qtd. & $\begin{array}{c}\text { Honorários } \\
\text { Médio Mensal }\end{array}$ & $\begin{array}{c}\text { Encargos } \\
\text { Mensal }\end{array}$ & $\begin{array}{c}\text { Custo Anual } \\
\text { (Salários+Encar gos) }\end{array}$ \\
\hline Consultor & 1 & $2.500,00$ & 908,00 & $40.896,00$ \\
\hline TOTAL MO & $\mathbf{1}$ & $\mathbf{2 . 5 0 0 , 0 0}$ & $\mathbf{9 0 8 , 0 0}$ & $\mathbf{4 0 . 8 9 6 , 0 0}$ \\
\hline
\end{tabular}

Fonte: Desenvolvido pelos autores do projeto (2016).

Já os honorários dos consultores terão o custo mensal de R \$ 2.500,00 e anual, somando salários+encargos de R \$ $40.896,00$.

\begin{tabular}{|l|l|l|}
\hline \multicolumn{3}{|c|}{ Quadro 8: Premissas. } \\
\hline 1 & Previsão de inflação & $6,22 \%$ \\
\hline 2 & Cotação do Dólar & $\mathrm{R} \$ 3,59$ \\
\hline 3 & Carga tributária & $35,13 \%$ do PIB \\
\hline
\end{tabular}

*carga tributária:site. www.tributoedireito.blogsport.com/2011/03/cargatributaria

Fonte: Desenvolvido pelos autores do projeto (2016).

\section{Atividades chave}

O foco da empresa será um atendimento premium de alta qualidade para o mercado de mel orgânico, hoje em dia carente de uma gestão profissional e com foco na satisfação do cliente. Teremos venda direta de produtos no varejo para os clientes.

Vendas de produtos e serviços diretos ao consumidor final, na qual a execução é no balcão da loja.

Nossas estratégias serão voltadas para o seguindo objetivo que é aumentar a habilidade dos parceiros para realizar suas próprias mudanças.

\begin{tabular}{|l|l|}
\hline \multicolumn{2}{|l|}{ Quadro 9: Estratégia: aumentar a habilidade do parceiro-chave para realizar suas próprias mudanças. } \\
\hline & \\
\hline $\begin{array}{l}\text { Maximizar seus pontos fortes, com um bom plano de comunicação, que inclui o envio de } \\
\text { informações periódicas aos clientes sobre produtos e serviços. }\end{array}$ & Estimado \\
\hline $\begin{array}{l}\text { Estratégia de estabilização, reduzindo os custos unitários das peças } \\
\text { oferecidas pela empresa. }\end{array}$ & Estimado \\
\hline Manter um bom preço dos produtos e investindo em personalização do atendimento & Estimado \\
\hline Frequentes desenvolvimentos e lançamentos de novos produtos e serviços & Estimado \\
\hline
\end{tabular}

Fonte: Desenvolvido pelos autores do projeto (2016).

Para o atendimento às demandas do futuro previstas neste plano, será adotado o seguinte Plano de Ação do Programa de desenvolvimento de parceiros: 


\begin{tabular}{|c|c|}
\hline \multicolumn{2}{|l|}{ Quadro 10: Etapas do Desenvolvimento de Parceiros. } \\
\hline DESCRIÇÃO & STATUS \\
\hline 1) Identificação da necessidade de melhorias & Estimado \\
\hline 2) Estabelecimento dos objetivos do projeto & Estimado \\
\hline 3) Definição do período de duração do projeto & Estimado \\
\hline 4) Definição da forma de financiamento do projeto & Estimado \\
\hline 5) Definição das informações que deverão ser disponibilizadas pela Empresa & Estimado \\
\hline 6) Definição da forma de avaliação das propostas submetidas pelos fornecedores & Estimado \\
\hline $\begin{array}{l}\text { 7) Definição da forma de avaliação dos resultados após intervenção nos } \\
\text { fornecedores }\end{array}$ & Estimado \\
\hline 8) Escolha dos fornecedores que participarão do projeto & Estimado \\
\hline 9) Identificação do perfil de cada fornecedor & Estimado \\
\hline 10) Acompanhamento aos fornecedores & Estimado \\
\hline
\end{tabular}

Fonte: Desenvolvido pelos autores do projeto (2016).

O quadro a seguir relaciona os procedimentos internos que compõe o processo de satisfação dos clientes.

Quadro 11: Checklist de Procedimentos internos que compõe o processo de satisfação do cliente.

\begin{tabular}{|c|l|c|}
\hline IT & \multicolumn{1}{|c|}{ DESCRIÇÃO } & S/N (SIM/NÃO) \\
\hline 1 & $\begin{array}{l}\text { O cliente é recebido com cortesia É lhe oferecido cafezinho, água ou suco? Caso } \\
\text { o mesmo deseje esperar, após o preenchimento do cadastro é indicada uma sala } \\
\text { de espera confortável, com TV e cafeteira, serviço de leva e } \\
\text { traz onde o mesmo poderá ficará à vontade? }\end{array}$ & \\
\hline 2 & $\begin{array}{l}\text { O lugar é mantido limpo e organizado? } \\
\text { Todos os processos são transparentes aos clientes, o que mostra honestidade e } \\
\text { credibilidade. Na atualidade, muitas empresas disponibilizam no site todas as } \\
\text { informações sobre a origem do produto. A empresa vai utilizar esse } \\
\text { procedimento/recurso? }\end{array}$ & \\
\hline
\end{tabular}

Fonte: Desenvolvido pelos autores do projeto (2016).

As normas externas de regulamentação do setor são as seguintes:

\begin{tabular}{|c|l|r|}
\hline \multicolumn{2}{|c|}{ Quadro 12: Legislação Aplicável. } \\
\hline 1 & $\begin{array}{l}\text { Constituição Federal do Brasil } \\
\text { de 1988 (CF/88) }\end{array}$ & \\
\hline 2 & $\begin{array}{l}\text { Ministério da agricultura e do } \\
\text { abastecimento }\end{array}$ & Instrução Normativa N ${ }^{\circ}$ 11, De 20 De Outubro De 2000. \\
\hline 3 & CONAMA & Resolução 346/2004 \\
\hline 4 & IBAMA & Instrução Normativa 07/2015 \\
\hline
\end{tabular}

Fonte: Desenvolvido pelos autores do projeto (2016). 
Custos Requeridos para Abertura da Empresa Valor Custo de Abertura

Os custos de abertura foram realizados através de um contador contratado que conduziu todo o processo de abertura. $\mathrm{O}$ custo foi de $\mathrm{R} \$ 900,00$. O prazo para a abertura é de 40 dias.

\section{Taxas}

As taxas pagas para a abertura da empresa e demais atos estão detalhadas abaixo:

\begin{tabular}{|c|c|}
\hline \multicolumn{2}{|l|}{ Quadro 13: Taxas. } \\
\hline Especificação dos Atos & $\begin{array}{l}\text { Agência na Região } \\
\text { Metropolitana (R\$) }\end{array}$ \\
\hline $\begin{array}{l}\text { Sociedades Empresariais: Contrato Social, alteração Contratual, Ata de Reunião } \\
\text { de Sócios, Ata de Assembléia de Sócios, Documento Substitutivo da Ata de Reunião } \\
\text { ou de Assembléia de Sócios }\end{array}$ & $\mathrm{R} \$ 42,00$ \\
\hline $\begin{array}{l}\text { Proteção ao Nome Empresarial: Registro de Proteção ao nome empresarial (Até } 3 \\
\text { Vias) }\end{array}$ & $\mathrm{R} \$ 28,00$ \\
\hline $\begin{array}{l}\text { Documentos de Arquivamento Obrigatório ou de Interesse: Procuração, } \\
\text { Instrumento de Nomeação, Alvará, Publicação ou Anotação de publicação de Ato de } \\
\text { Sociedade ou de empresário, Ata de Reunião do Conselho Fiscal, Comunicação de } \\
\text { Funcionamento Balanço Patrimonial e/ou Balanço de Resultado Econômico, } \\
\text { usufruto ou arrendamento de estabelecimento. }\end{array}$ & $\begin{array}{l}\mathrm{R} \$ 280,00 \text { cada ato } \\
(28,00)\end{array}$ \\
\hline $\begin{array}{l}\text { Pesquisa de nome empresarial idêntico ou semelhante: Por requerimento com até } \\
03 \text { nomes }\end{array}$ & gratuito \\
\hline Consulta a Documentos: Por empresa consultada & $\mathrm{R} \$ 10,00$ \\
\hline Certidões: Certidão de Inteiro Teor (por ato arquivado) & $\mathrm{R} \$ 16,00$ \\
\hline $\begin{array}{l}\text { Autenticação de Instrumentos de Escrituração de Empresário: Livro, conjunto } \\
\text { de folhas encadernadas sob a forma de livro ou conjunto de folhas contínuas }\end{array}$ & $\mathrm{R} \$ 16,00$ \\
\hline $\begin{array}{l}\text { Informações Cadastrais - Cadastro Estadual de Empresas Mercantis: } \\
\text { Informações fornecidas através de meio magnético ou CD Rom para listagem com } \\
\text { até } 500 \text { registros (pedido mínimo) }\end{array}$ & $\mathrm{R} \$ 50,00$ \\
\hline $\begin{array}{l}\text { Divulgação: Revistas, periódicos, publicações diversas, Informações em Mídia } \\
\text { Eletrônica e outros Assemelhados: Relatório Estatístico por atividade }\end{array}$ & $\mathrm{R} \$ 20,00$ \\
\hline TOTAL $>>>>>>>>>>>>>>>>1$ & $R \$ 462,00$ \\
\hline
\end{tabular}

Fonte: JUCESP/Tabela de Preços.

Como se trata de uma sociedade empresária, o único imposto é o IPTU, conforme abaixo:

\begin{tabular}{|l|l|}
\hline Quadro 14: Impostos. & Valor Anual (R\$) \\
\hline IPTU - Imposto Predial e Territorial & $6.000,00$ \\
\hline
\end{tabular}

Fonte: Desenvolvido pelos autores do projeto (2016). 


\section{Documentos Necessários}

Os documentos necessários para abertura de empresa foram:

a) RG dos sócios;

b) CPF dos sócios;

c) Conta de Luz dos sócios;

d) IPTU da sede da Empresa.

NOTA: Considerando que o imóvel da empresa foi alugado foi necessário ainda uma cópia do contrato de locação registrado.

\section{Parcerias Chave}

As parcerias chave serão os comerciantes que são vendedores de mel.

\section{Estrutura de Custos}

Vendas de produtos e serviços diretos ao consumidor final, na qual a execução é no balcão da loja.

Nossas estratégias serão voltadas para o seguindo objetivo que é aumentar a habilidade dos parceiros para realizar suas próprias mudanças.

\begin{tabular}{|l|l|}
\hline Quadro 15: Estratégia: aumentar a habilidade do parceiro-chave para realizar suas próprias \\
mudanças. & \\
\hline & $\begin{array}{l}\text { Maximizar seus pontos fortes, com um bom plano de comunicação, que inclui o envio de } \\
\text { informações periódicas aos clientes sobre produtos e serviços. }\end{array}$ \\
\hline $\begin{array}{l}\text { Estratégia de estabilização, reduzindo os custos unitários das peças oferecidas pela empresa. } \\
\text { Manter um bom preço dos produtos e investindo em personalização } \\
\text { do atendimento }\end{array}$ & Estimado \\
\hline Frequentes desenvolvimentos e lançamentos de novos produtos e serviços & Estimado \\
\hline
\end{tabular}

Fonte: Desenvolvido pelos autores do projeto (2016).

Para o atendimento às demandas do futuro previstas neste plano, será adotado o seguinte Plano de Ação do Programa de desenvolvimento de parceiros: 


\begin{tabular}{|l|l|}
\hline \multicolumn{2}{|c|}{ Quadro 16: Etapas do Desenvolvimento de Parceiros. } \\
\hline DESCRIÇÃO & STATUS \\
\hline 1) Identificação da necessidade de melhorias & Estimado \\
\hline 2) Estabelecimento dos objetivos do projeto & Estimado \\
\hline 3) Definição do período de duração do projeto & Estimado \\
\hline $\begin{array}{l}\text { 4) Definição da forma de financiamento do projeto } \\
\text { disponibilizadas pela Empresa }\end{array}$ & Estimado \\
\hline $\begin{array}{l}\text { 6) Definição da forma de avaliação das propostas } \\
\text { submetidas pelos fornecedores }\end{array}$ & Estimado \\
\hline $\begin{array}{l}\text { DESCRIÇÃo das informac̃es que deverão ser } \\
\text { 7) Definição da forma de avaliação dos resultados após } \\
\text { intervenção nos fornecedores }\end{array}$ & STATUS \\
\hline 8) Escolha dos fornecedores que participarão do projeto & Estimado \\
\hline $\begin{array}{l}\text { 9) Identificação do perfil de cada fornecedor } \\
\text { 10) Acompanhamento aos fornecedores }\end{array}$ & Estimado \\
\hline
\end{tabular}

Fonte: Desenvolvido pelos autores do projeto (2016).

- Estrutura de Custos

Custos Requeridos para Abertura da Empresa Valor Custo de Abertura

Os custos de abertura foram realizados através de um contador contratado que conduziu todo o processo de abertura. O custo foi de $\mathrm{R} \$ 900,00$. O prazo para a abertura é de 40 dias.

\section{Taxas}

As taxas pagas para a abertura da empresa e demais atos estão detalhadas abaixo: 


\begin{tabular}{|c|c|}
\hline \multicolumn{2}{|l|}{ Quadro 17: Taxas. } \\
\hline Especificação dos Atos & $\begin{array}{l}\text { Agência na Região } \\
\text { Metropolitan a (R\$) }\end{array}$ \\
\hline $\begin{array}{l}\text { Sociedades Empresariais: Contrato Social, alteração Contratual, Ata de Reunião de Sócios, } \\
\text { Ata de Assembléia de Sócios, Documento Substitutivo da Ata de Reunião ou de Assembléia } \\
\text { de Sócios }\end{array}$ & $\mathrm{R} \$ 42,00$ \\
\hline Proteção ao Nome Empresarial: Registro de Proteção ao nome empresarial (Até 3 Vias) & $\mathrm{R} \$ 28,00$ \\
\hline $\begin{array}{l}\text { Documentos de Arquivamento Obrigatório ou de Interesse: Procuração, Instrumento de } \\
\text { Nomeação, Alvará, Publicação ou Anotação de publicação de Ato de Sociedade ou de } \\
\text { empresário, Ata de Reunião do Conselho Fiscal, Comunicação de Funcionamento Balanço } \\
\text { Patrimonial } \quad \text { e/ou Balanço de Resultado Econômico, usufruto ou arrendamento de } \\
\text { estabelecimento }\end{array}$ & $\begin{array}{c}\mathrm{R} \$ 280,00 \text { cada ato } \\
(28,00)\end{array}$ \\
\hline $\begin{array}{l}\text { Pesquisa de nome empresarial idêntico ou semelhante: Por requerimento com até } 03 \\
\text { nomes }\end{array}$ & gratuito \\
\hline Consulta a Documentos: Por empresa consultada & $\mathrm{R} \$ 10,00$ \\
\hline Certidões: Certidão de Inteiro Teor (por ato arquivado) & $\mathrm{R} \$ 16,00$ \\
\hline Especificação dos Atos & $\begin{array}{l}\text { Agência na Região } \\
\text { Metropolitan a (R\$) }\end{array}$ \\
\hline $\begin{array}{l}\text { Autenticação de Instrumentos de Escrituração de Empresário: Livro, conjunto de folhas } \\
\text { encadernadas sob a forma de livro ou conjunto de folhas contínuas }\end{array}$ & $\mathrm{R} \$ 16,00$ \\
\hline $\begin{array}{l}\text { Informações Cadastrais - Cadastro Estadual de Empresas Mercantis: Informações } \\
\text { fornecidas através de meio magnético ou CD Rom para listagem com até } 500 \text { registros } \\
\text { (pedido mínimo) }\end{array}$ & $\mathrm{R} \$ 50,00$ \\
\hline $\begin{array}{l}\text { Divulgação: Revistas, periódicos, publicações diversas, Informações em Mídia Eletrônica e } \\
\text { outros Assemelhados: Relatório Estatístico por atividade }\end{array}$ & $\mathrm{R} \$ 20,00$ \\
\hline TOTAL $\gg>>>>>>>>>>>>>>1$ & $\mathbf{R} \$ 462,00$ \\
\hline
\end{tabular}

Fonte: JUCESP/Tabela de Preços.

\begin{tabular}{|l|c|c|}
\hline \multicolumn{3}{|c|}{ Quadro 18: Investimento inicial. } \\
\hline Contas & Valor & $\mathbf{\%}$ \\
\hline INVESTIMENTO FIXO & $\mathbf{4 6 8 . 4 6 2 , 1 6}$ & $\mathbf{8 0 , 6 8 \%}$ \\
CAPITAL DE GIRO & $\mathbf{9 9 . 6 7 2 , 8 0}$ & $\mathbf{1 7 , 1 7 \%}$ \\
Salarios + Pro Labore + Encargos & $33.278,46$ & $33,39 \%$ \\
Despesas fixas e variáveis & $66.394,33$ & $66,61 \%$ \\
DIVERSOS & $\mathbf{1 2 . 5 0 0 , 0 0}$ & $\mathbf{2 , 1 5 \%}$ \\
Registro / Regularização & $1.600,00$ & $12,80 \%$ \\
Campanha de lançamento e coquetel & $10.900,00$ & $87,20 \%$ \\
\hline TOTAL & $\mathbf{5 8 0 . 6 3 4 , 9 6}$ & $\mathbf{1 0 0 , 0 0 \%}$ \\
\hline
\end{tabular}

Fonte: Desenvolvido pelos autores do projeto (2016).

O investimento inicial da empresa como visto no quadro acima será de 580.634,96, esse investimento compreende o 
investimento fixo, capital de giro e diversos.

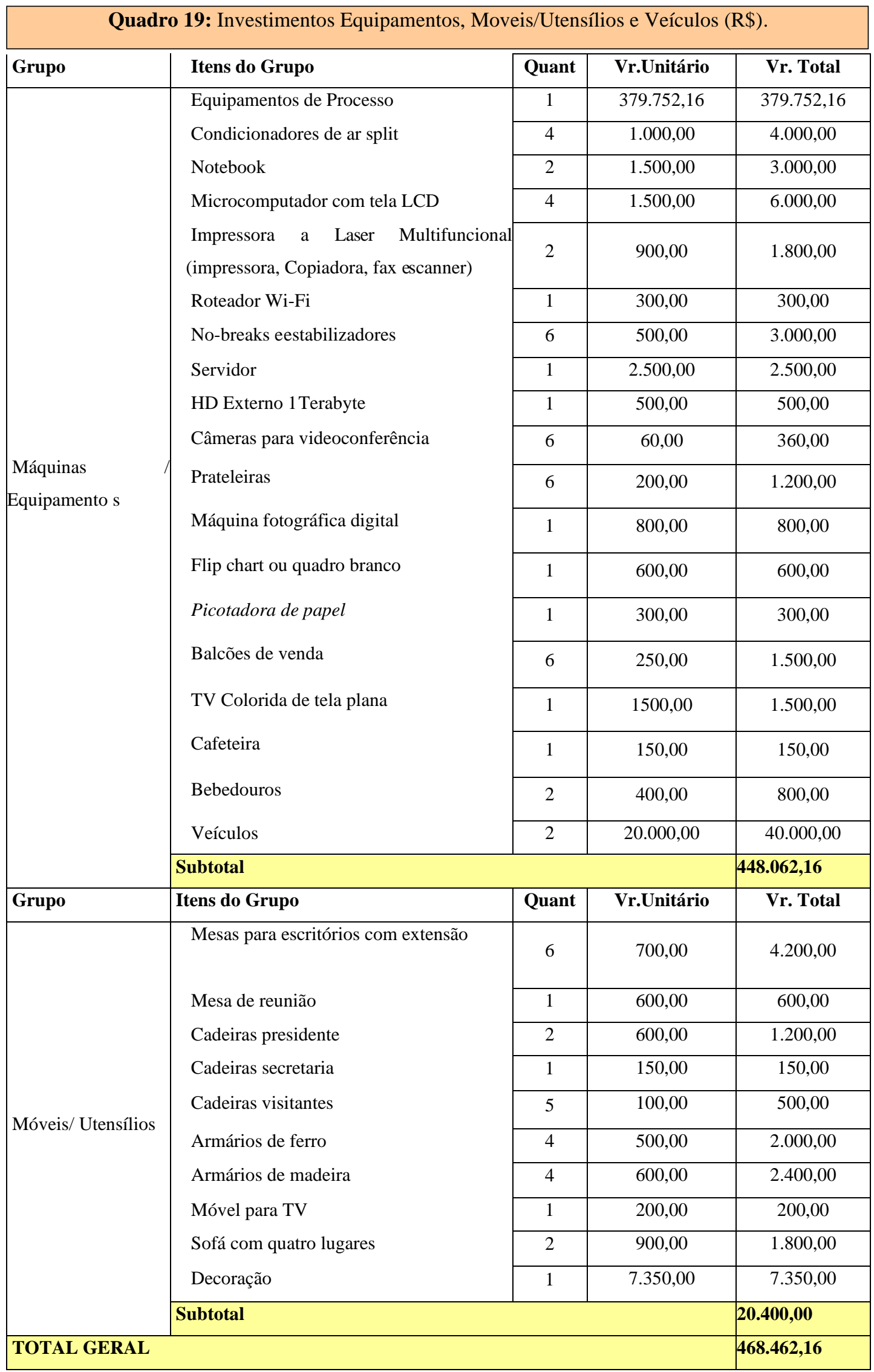

Fonte: Desenvolvido pelos autores do projeto (2016). 
Verifica-se na tabela acima que o investimento em Equipamentos, Movéis/Utensílios e Veículos será de R \$468.462,16.

\section{Considerações Finais}

Na nova realidade global encarada pelas organizações empresariais, sobretudo após o final do século passado, seja no âmbito mercadológico ou de recursos humanos e financeiros, fica cada vez mais evidente a importância de uma boa gestão para a continuidade de qualquer negócio, assim como para as decisões de investimentos em empreendimentos corporativos ou inovadores.

O destaque para a gestão dá-se ao fato de uma competitividade cada vez mais acirrada em todos os mercados e a busca dos clientes por qualidade no atendimento, novas formas e prazos de pagamento e entrega o que faz as empresas constantemente investir em novos métodos, processos, pesquisas e tecnologias para que não sejam sugadas pelo avanço notado diariamente. Porém, avaliar a qualidade desses investimentos pode garantir um passo à frente no mercado e ter destaque e preferência do seu cliente final.

Nesse trabalho, podemos observar a importância dos cuidados que se deve ter ao realizar qualquer investimento. Acima disso, conhecer as ferramentas adequadas e as formas de aplicá-las para que haja segurança nas tomadas de decisão, que podem definir o rumo que a empresa tomará a partir das ações tomadas com base nos instrumentos financeiros utilizados. Para se tomar uma decisão de grande investimento, os aspectos mercadológicos e de necessidade do cliente, também são peças fundamentais para que efetivamente um projeto de investimento esteja embasado em fundamentos reais e que possam ser praticados. Um plano financeiro é válido, somente se ele tiver como base as premissas ou os motivos pelo qual ele está sendo desenvolvido. Um ponto importante a ser levado em consideração é o tempo: tempo de produção do projeto, bem como tempo do lançamento aliado as condições de mercado e necessidades ou desejo dos clientes finais, para que o produto ou serviço não seja lançado de forma obsoleta, ou haja vazamento nas informações confidenciais do projeto e cheguem às mãos de um concorrente. Vale observar que o plano financeiro é uma das últimas etapas que são desenvolvidas em um business plan, nele são contidas as demais informações levantadas em outras etapas no planejamento, como: contratação de pessoal, compra de máquinas, equipamentos, custos fixos, despesas administrativas, etc.

Entender o que o mercado precisa ou deseja é de extrema importância, pois assim é possível determinar as variáveis dos recursos necessários e assim, otimizar os recursos despendidos para sua realização, para que o produto ou serviço se materialize de forma perceptível ao cliente e de forma financeira para os acionistas, sendo sustentável e rentável. Portanto, o plano financeiro deve estar focado naquilo que realmente importa e agrega valor para a companhia e seus stakeholders

Ao vender mel no mercado, é preciso levar em consideração uma série de questões que não podemos ignorar é que muito poucos comerciantes que não têm planos econômicos e, portanto, acabam falhando, por isso temos de ter um plano econômico também definido para este tipo de negócio de venda de mel.

A Internet hoje tornou-se uma ferramenta poderosa para vender mel, e é por isso que devemos aproveitar ao máximo e publicar a venda em todos os meios midiáticos disponíveis.

Nenhum investimento pode ou deve ser realizado sem que o retorno esperado seja ao menos previsto dentro de um plano financeiro, claro que há fatores externos não controláveis, como catástrofes ambientais e demais possibilidades, porém é importante esclarecer que o retorno financeiro é primordial para tangibilizar qualquer investimento.

Finalmente, podemos concluir que o plano de custos, está embasado em fundamentos reais de mercado aliado a mais refinada análise de investimento e retorno, sendo mais importante, de forma positiva, demonstrando que o projeto é promissor e seu retorno atrativo do ponto de vista financeiro.

Recomenda-se para uma futura investigação a realização de um estudo de caso com potenciais consumidores, essas informações serão de grande valia para o amplo conhecimento do mercado e as necessidades dos consumidores. 


\section{Referências}

Afonso, R. A. E. (2009). DOAR versus Fluxo de Caixa. Revista IOB - Temática Contábil e Balanços, Boletim 18.

Associação Brasileira de Capital de Risco - ABCR. (2003) Pesquisa de capital de risco para o primeiro semestre de 2003.

Baldin, D. (2003). Como preparar seu plano de negócios para investidores de risco. Seminário na incubadora de empresas INETEC,

Epers e Rogers. (2009). Total de Marketing de Relacionamento, LondoButterworth- Heinemann.

Fernández, P. (2001). Company valuation methods. The most common errors in valuation. PricewaterhouseCoopers Professor of Corporate Finance. 25p. Madrid. IESE Business School.

Filho, A. C. (2009) Demonstração dos fluxos de caixa: Uma ferramenta indispensável para administrar sua empresa. Atlas.

Finocchio Jr., José. (2013). Project Model Canvas - Gerenciamento de Projetos sem Burocracia. Editora Campus.

Gil, A. C. (2001). Métodos e Técnicas de pesquisa social. Atlas.

Iudícibus, S de, Martins, E., \& Gelbcke, E. R. (2013). Manual de contabilidade das sociedades por ações: aplicável às demais sociedades. (6a ed.), Atlas.

Kotler, P. (2005). Marketing do Século XXI. Como criar, conquistar e dominar mercados.

Tradução Bazán Tecnologia e Lingüística, Cristina Bazán, Editora Futura.

Kotler, P. (2000). Administração de marketing: a edição do novo milênio. (10a ed.), Prentice Hall.

Kunz, E. L. (2008). O ser do valor e valores. Porto Alegre: Sulina.

Lakatos, E. M., \& Marconi, M. de A. (1991). Fundamentos de Metodologia Científica. (3a ed.), Atlas.

Lovelock, C., \& Wright, L. (2005). Serviços: marketing e gestão.

Martins, E. (2011). Avaliação de empresas: Da mensuração contábil à econômica. Atlas.

Martins, E. (2011). Contabilidade versus Fluxo de Caixa. Caderno de Estudos, FIPECAFI, Abril.

Ministério da Agricultura, Pecuária e Abasteciment. (2014). Secretaria de Política Agrícola (SPA) e Instituto Interamericano de Cooperação pra a Agricultura (IICA). Cadeias Produtivas de Flores e Mel. Série Agronegócios, Brasília.

Morten, T. et al. (2009). Qual é a sua estratégia de gestão do conhecimento? Harvard Business Review77 (2).

Nonaka, I. (2011). A empresa criadora de conhecimento. Harvard Business Review69.6.

Muller, A. N., \& Teló, A. R. (2013). Modelos de avaliação de empresas. Revista da FAE, 6, 97-112

Osterwalder, A., \& Pigneur, Y. (2011). Business Model Canvas Inovação em Modelos de Negócios. Um Manual para Visionários, Inovadores e Revolucionários. Alta Books.

Pavani, C. (2012). O capital de Risco no Brasil: Conceito, Evolução e Perspectivas. E-Papers.

Portal Paraíba Total. Produção de mel cresce na Paraíba e atividade pode gerar lucro de mais de 300\%. http://www.paraibatotal.com.br/noticias/2016/07/04/56726-producao-de-mel-cresce-na- paraiba-e-atividade-pode-gerar-lucro-de-mais-de-300

Porter, M. E. (2002). Estratégia Competitiva: Técnicas para análise de indústrias e da concorrência. (7a ed.), Campus.

Porter, M. A. Competição: estratégias competitivas essenciais. (7a ed.), Campus.

Ross, S. A. et al. (2002). Administração Financeira. Atlas.

Rasila, H. M., \& Gersberg, N. F. (2007). Serviço de qualidade em serviços de manutenção terceirizados facilidade. Jornal do Imobiliário Corporativo. 9, -49, 2007

Roesch, A. (1999). Qualidade na prestação de serviços. Revista Produção, 17, 435-453

Ribeiro, L. (2015). Marketing Social e Comportamento do Consumidor. Pearson Education

Russel, R. (2002). Operations: management and student CD: International Edition. (4a ed.), Prentice Hall.

Santi Filho, A., \& Olinquevitch, J. L. (2014). Análise de balanços para controle gerencial: enfoque sobre o fluxo de caixa e previsão de rentabilidade. 3 ed. Atlas.

Souza, A. M., Griebeler, D., Godoy, L. P. (2007). Qualidade na prestação de serviços fisioterápicos - estudo de caso sobre expectativas e percepções dos clientes. Revista Produção, 17, 435-453

Stefano, N. S. et al. (2008). Satisfação dos Clientes Interno e Externo Mensurada Através da Escala Servqual e do Modelo GAP em uma Empresa Prestadora de Serviços. IV Congresso Nacional de Excelência em Gestão: Responsabilidade Socioambiental das Organizações Brasileiras Niteroi, RJ, Brasil. 
Research, Society and Development, v. 10, n. 7, e52710715719, 2021

(CC BY 4.0) | ISSN 2525-3409 | DOI: http://dx.doi.org/10.33448/rsd-v10i7.15719

Semenik, R. J., \& Bamossy, G. J. (1995). Princípios de marketing: uma perspectiva global. Makron.

SEBRAE. Informações de mercado sobre mel e derivados da colméia. Série Mercado. www.sebrae.com.br

Souza, F. J. M de. (2004). Os 50 mandamentos do marketing. Makron Books.

Souza, R. P. (2009). Reflexões sobre o marketing de relacionamento no mercado consumidor, Journal of the Academy of Marketing da Ciência, $23,272-77$.

Stone, A. (2002). Cooperação e competição: Um darwinista Síntese de Marketing de Relacionamento, European Journal of Marketing, 34 (6).

Todo el Campo. Brasil abrió su mercado a la miel fraccionada. Acesso em http://www.todoelcampo.com.uy/espanol/brasil-abrio-su-mercado-a-la-mielfraccionada-15?nid=32773.

Trigueiro,C. M. (1999). Marketing e Turismo:como planejar o marketing turístico para uma localidade. :Qualitymark.

Zanluca, J. C. Contabilidade de custos. Portal de Contabilidade. http://www.portaldecontabilidade.com.br/guia/custos_direitos.htm

Vaz,G. N. (2009). Marketing Turístico .Pioneira.

Zineldin, M. (2010). Marketing tecnológico. Marketing e Planejamento , 18 (1). 